\title{
Article
}

\section{Additions to Fissuroma and Neoastrosphaeriella (Aigialaceae, Pleosporales) from palms}

\author{
Zhang $\mathrm{SN}^{1,2,3,4}$, Hyde $\mathrm{KD}^{4}$, Jones EBG ${ }^{5}$, Cheewangkoon $\mathrm{R}^{3}$ and Liu $\mathrm{JK}^{1 *, 2}$ \\ ${ }^{1}$ School of Life Science and Technology, University of Electronic Science and Technology of China, Chengdu 611731, \\ P.R. China. \\ ${ }^{2}$ Guizhou Key Laboratory of Agricultural Biotechnology, Guizhou Academy of Agricultural Science, Guiyang 550006, \\ P.R. China. \\ ${ }^{3}$ Department of Entomology and Plant Pathology, Faculty of Agriculture, Chiang Mai University, Chiang Mai 50200, \\ Thailand. \\ ${ }^{4}$ Center of Excellence in Fungal Research, Mae Fah Luang University, Chiang Rai 57100, Thailand. \\ ${ }^{5}$ Deptartment of Botany and Microbiology, College of Science, King Saud University, P.O Box 2455 Riyadh 11451, \\ Kingdom of Saudi Arabia.
}

Zhang SN, Hyde KD, Jones EBG, Cheewangkoon R, Liu JK 2020 - Additions to Fissuroma and Neoastrosphaeriella (Aigialaceae, Pleosporales) from palms. Mycosphere 11(1), 269-284, Doi 10.5943/mycosphere/11/1/5

\begin{abstract}
Recent examination of palm fungi led to the discovery of a group of fissuroma-like taxa, which share the following morphological features: slit-like ascomata, carbonaceous peridium, trabeculate pseudoparaphyses, cylindric-clavate or obclavate asci and fusiform, septate ascospores. Multi-gene phylogenetic analyses based on a combined ITS, LSU, SSU and TEF1- $\alpha$ sequence data support the establishment of Fissuroma palmae sp. nov. and Neoastrosphaeriella phoenicis sp. nov. Fissuroma caryotae and $N$. aquatica are also recovered as new host records from terrestrial palms. Fissuroma palmae is phylogenetically close to $F$. caryotae with strong support, but differs from $F$. caryotae in the appearance of pale brown mature ascospores, and the dimensions of asci and ascospores. Neoastrosphaeriella phoenicis is associated with submerged petioles of Phoenix paludosa in mangroves, providing an insight of a new habitat for Neoastrosphaeriella species. The hyaline to pale brown, fusiform, 1-3-septate, guttulate, verrucose ascospores of $N$. phoenicis distinguish it from other existing Neoastrosphaeriella species. Additional new taxa and their morphological features, ecological occurrence, as well as phylogenetic circumscription of genera in Aigialaceae are provided and discussed.
\end{abstract}

Key words -2 new taxa - Arecaceae - Dothideomycetes - Phylogeny - Taxonomy

\section{Introduction}

The family Aigialaceae was introduced by Suetrong et al. (2009) to accommodate three marine genera Aigialus Kohlm. \& S. Schatz, Ascocratera Kohlm. and Rimora Kohlm., Volkm.Kohlm., Suetrong, Sakay. \& E.B.G. Jones. Subsequently, two genera Fissuroma J.K. Liu, R. Phookamsak, E.B.G. Jones \& K.D. Hyde and Neoastrosphaeriella J.K. Liu, E.B.G. Jones \& K.D. Hyde from terrestrial habitats were included based on multi-gene phylogeny (Liu et al. 2011). Members of Aigialaceae are characterized by carbonaceous ascomata with slit-like or crater-like 
ostioles, trabeculate pseudoparaphyses, cylindric-clavate or obclavate asci and septate ascospores with a sheath or apical appendages (Suetrong et al. 2009, Liu et al. 2011, Hyde et al. 2013). The ascomata and ascospore morphologies are remarkable features to distinguish taxa in this family. Aigialus, the type genus of Aigialaceae, has immersed ascomata with apical slit-like ostioles and muriform brown ascospores with terminal appendages (Suetrong et al. 2009, Zhang et al. 2012). While the monotypic genus Ascocratera is distinct in having crater-like, erumpent to superficial ascomata, and ellipsoidal, 1-septate (3-septate when senescent) ascospores (Kohlmeyer 1986, Suetrong et al. 2009, Zhang et al. 2012). Fissuroma, Neoastrosphaeriella and Rimora share similar morphological features: slit-like, erumpent to superficial ascomata, and fusiform ascospores. However, Rimora, which is typified by $R$. mangrovei ( $\equiv$ Lophiostoma mangrovei), can be distinguished by its broad oblong ascomata, thick peridium, cylindrical asci and 3-septate ascospores (Kohlmeyer \& Vittal 1986, Suetrong et al. 2009, Liu et al. 2011). The phenotypic distinction between Fissuroma and Neoastrosphaeriella is not very clear but the two genera constitute distinct clades in the family Aigialaceae.

Liu et al. (2011) introduced Fissuroma to accommodate species with slit-like ascomata that were excluded from Astrosphaeriella Syd. \& P. Syd., with F. maculans (Rehm) J.K. Liu, E.B.G. Jones \& K.D. Hyde as the type species (三 Metasphaeria maculans Rehm), and the combination $F$. aggregata (I. Hino \& Katum.) R. Phookamsak., J.K. Liu, E.B.G. Jones \& K.D. Hyde (三 Melanopsamma aggregate I. Hino \& Katum.). However, Phookamsak et al. (2015) named one of the represented $F$. aggregate strains as $F$. neoaggregata Phookamsak \& K.D. Hyde, and introduced F. bambusae Phookamsak \& K.D. Hyde, F. fissuristoma (J. Fröhl et al.) Phookamsak \& K.D. Hyde and F. thailandicum Phookamsak \& K.D. Hyde. Thereafter, Wanasinghe et al. (2018) discovered $F$. calami Wanas., E.B.G. Jones \& K.D. Hyde and F. caryotae Wanas., E.B.G. Jones \& K.D. Hyde from terrestrial palms, which are quite similar in morphology but phylogenetically distinct. Tennakoon et al. (2018) described F. taiwanense Tennakoon, C.H. Kuo \& K.D. Hyde, which differs from the other species by broad cylindrical to obclavate asci and broad ascospores with distinctive long apical and basal appendages. Niranjan \& Sarma (2018) reported F. kavachabeejae M. Niranjan \& V.V. Sarma and F. microsporum M. Niranjan \& V.V. Sarma in India but without molecular data. Eleven Fissuroma epithets are recorded in Index Fungorum (November, 2019), which are characterized by conical, hemisphaerical, carbonaceous ascomata, with flattened base and slit-like ostioles, trabeculate pseudoparaphyses, cylindric-clavate, short pedicellate asci, and 1septate, fusiform ascospores (Liu et al. 2011, Phookamsak et al. 2015, Niranjan \& Sarma 2018, Tennakoon et al. 2018, Wanasinghe et al. 2018).

During our investigation of palm fungal diversity, we collected five fissuroma-like taxa from palms in mangrove and terrestrial habitats in Thailand. Further morphological comparison and molecular phylogeny revealed that these collections belong to Fissuroma and Neoastrosphaeriella, respectively. In this study, a multi-gene phylogeny based on DNA sequence data and morphological comparisons are performed to identify the species. Two new species and two new host records are introduced to Fissuroma and Neoastrosphaeriella.

\section{Materials \& Methods}

\section{Specimens collection, examination and single spore isolation}

Decayed rachides/petioles of palms were collected from mangrove and terrestrial habitats in Thailand (detailed information of collection sites and hosts are listed in the taxonomy section). Specimens were sorted and placed into plastic bags in the field along with the environment, geographic location and host information. Fungal fruiting bodies were observed using Motic SMZ 168 stereo microscope and free hand sections of fruiting bodies were made into slides mounted in water by using a syringe needle. Morphological characters were observed using a Carl Zeiss stereo microscope fitted with an AxioCam ERC 5S camera and photographed by a Nikon ECLIPSE 80i compound microscope fitted with a Canon EOS 600D digital camera. Measurements were taken by Tarosoft Image Frame Work program v. 0.9.7 (Liu et al. 2010) and images used for figures 
processed with Adobe Photoshop CS6 Extended v. 13.0 software. Isolations were obtained from single spore as described in Chomnunti et al. (2014). The strains isolated in this study were deposited in Mae Fah Luang University Culture Collection (MFLUCC). Herbarium specimens were deposited at the herbarium of Mae Fah Luang University (MFLU), Chiang Rai, Thailand and Herbarium of Cryptogams, Kunming Institute of Botany Academia Sinica (KUN-HKAS), Kunming, China. New taxa are established based on recommendations as outlined by Jeewon \& Hyde (2016). The scientific names of the new taxa were registered in Index Fungorum and the FacesofFungi (Jayasiri et al. 2015).

\section{DNA extraction, PCR amplification and sequencing}

Fungal genomic DNA were extracted from fresh mycelia scraped from the margin of a colony on PDA that was incubated at $25-28^{\circ} \mathrm{C}$ for one month, by following the manufacturer's instructions of the Ezup Column Fungi Genomic DNA Purification Kit (Sangon Biotech (Shanghai) Co., Ltd, China). In the case of failure to obtain pure cultures, the genomic DNA was extracted from fruiting bodies by using the E.Z.N.A. TM Forensic DNA Extraction Kit (OMEGA Bio-Tek, D3591-01, Norcross, GA, U.S.A.). Four gene regions were used for polymerase chain reaction (PCR) of the new collections: the internal transcribed spacers (ITS: ITS1-5.8S-ITS2), the large subunit of the nuclear ribosomal RNA genes (LSU), the small subunit of the nuclear ribosomal RNA (SSU), and the translation elongation factor-1 alpha (TEF1- $\alpha$ ). The primers used were ITS5/ITS4 for ITS (White et al. 1990), LR0R and LR5 for LSU (Vilgalys \& Hester 1990), NS1/NS4 for SSU (White et al. 1990) and EF1-983F/EF1-2218R for TEF1- $\alpha$ (Rehner 2001). The


$2 \times$ PCR MasterMix (TIANGEN Co., China), $1 \mu \mathrm{L}$ DNA template and $1 \mu \mathrm{L}$ of each primer. The PCR thermal cycle program for ITS, LSU, SSU and TEF1- $\alpha$ amplification were as follows: initial denaturing step of $94^{\circ} \mathrm{C}$ for 3 mins, followed by 40 cycles of denaturation at $94^{\circ} \mathrm{C}$ for 45 seconds, annealing at $56^{\circ} \mathrm{C}$ for 50 seconds, elongation at $72^{\circ} \mathrm{C}$ for $1 \mathrm{~min}$, and final extension at $72^{\circ} \mathrm{C}$ for 10 mins. Purification and sequencing of PCR products were carried out with primers mentioned above at Sangon Biotech (Shanghai) Co., Ltd, China.

\section{Sequence alignment and phylogeny analyses}

A concatenated dataset of the ITS, LSU, SSU and TEF1- $\alpha$ sequences was used for phylogenetic analyses with the inclusion of reference taxa from GenBank (Table 1). Sequences were aligned using MAFFT v.7 (http://mafft.cbrc.jp/alignment/server/) (Katoh \& Standley 2013) and then checked visually and manually optimized using BioEdit v.7.0.9 (Hall 1999). Taxa of Aigialaceae and representative families and genera in Pleosporales were included in the analyses. Maximum likelihood (ML), Maximum parsimony (MP) and Bayesian analyses were carried out and the detail procedures were followed Zhang et al. (2018, 2019). Phylogenetic tree was visualized by FigTree v.1.4.2 (Rambaut 2014). The phylogenetic tree and DNA sequence alignment were deposited in TreeBASE (study accession URL:

http://purl.org/phylo/treebase/phylows/study/TB2:S25366).

Table 1 Taxa those were included in this study and their GenBank accession numbers. The type strains are indicated with superscript ${ }^{\mathrm{T}}$ and new generated strains are in bold.

\begin{tabular}{llllll}
\hline \multirow{2}{*}{ Taxa } & \multirow{2}{*}{ Strains/vouchers } & \multicolumn{4}{l}{ GenBank accession numbers } \\
\cline { 3 - 6 } & & ITS & LSU & SSU & TEF1-a \\
\hline Acuminatispora palmarum & MFLUCC 18-0264 T & MN749105 & MH390437 & MH390401 & MH399248 \\
Acuminatispora palmarum & MFLUCC 18-0460 & MN749106 & MH390438 & MH390402 & MH399249 \\
Aigialus grandis & BCC 18419 & - & GU479774 & GU479738 & GU479838 \\
Aigialus mangrovis & BCC 33563 & - & GU479776 & GU479741 & GU479840 \\
Aigialus parvus & BCC 18403 & - & GU479778 & GU479744 & GU479842 \\
\hline
\end{tabular}


Table 1 Continued.

\begin{tabular}{|c|c|c|c|c|c|}
\hline \multirow{2}{*}{ Taxa } & \multirow{2}{*}{ Strains/vouchers } & \multicolumn{4}{|c|}{ GenBank accession numbers } \\
\hline & & ITS & LSU & SSU & TEF1- $\alpha$ \\
\hline Aigialus rhizophorae & BCC 33572 & - & GU479780 & GU479745 & GU479844 \\
\hline Ascocratera manglicola & BCC 09270 & - & GU479782 & GU479747 & GU479846 \\
\hline Astrosphaeriella bambusae & $\underset{\mathbf{T}}{\operatorname{MFLUCC}} 13-0230$ & - & KT955461 & - & KT955424 \\
\hline Astrosphaeriella fusispora & MFLUCC 10-0555 & JN846719 & KT955462 & KT955443 & KT955425 \\
\hline Astrosphaeriella stellata & KT 998 & _- & AB524592 & AB524451 & - \\
\hline $\begin{array}{l}\text { Astrosphaeriellopsis } \\
\text { bakeriana }\end{array}$ & CBS 115556 & - & GU301801 & - & GU349015 \\
\hline $\begin{array}{l}\text { Astrosphaeriellopsis } \\
\text { bakeriana }\end{array}$ & $\underset{\mathbf{T}}{\operatorname{MFLUCC}} 11-0027$ & - & JN846730 & JN846740 & - \\
\hline $\begin{array}{l}\text { Astrosphaeriellopsis } \\
\text { caryotae }\end{array}$ & MFLUCC 13-0832 & - & MF588991 & MF588981 & MF588974 \\
\hline $\begin{array}{l}\text { Astrosphaeriellopsis } \\
\text { caryotae }\end{array}$ & $\underset{\mathbf{T}}{\operatorname{MFLUCC}} 13-0833$ & - & MF588992 & MF588982 & - \\
\hline Delitschia chaetomioides & SMH 3253.2 & - & GU390656 & - & - \\
\hline Delitschia winteri & CBS 225.62 & _ & DQ678077 & DQ678026 & DQ677922 \\
\hline Fissuroma aggregata & KT 984 & _- & AB524591 & AB524450 & AB539105 \\
\hline Fissuroma aggregata & KT 767 & _- & AB524590 & AB524449 & - \\
\hline Fissuroma bambusae & $\underset{\mathbf{T}}{\operatorname{MFLUCC}} 11-0160$ & - & KT955468 & KT955448 & KT955430 \\
\hline Fissuroma calami & MFLUCC $13-0836^{\mathrm{T}}$ & - & MF588993 & MF588983 & MF588975 \\
\hline Fissuroma caryotae & MFLU $17-1253^{\mathrm{T}}$ & _ & MF588996 & MF588986 & MF588979 \\
\hline Fissuroma caryotae & MFLUCC 16-1383 & MN735992 & MN712335 & MN699322 & MN744228 \\
\hline Fissuroma maculans & MFLUCC $10-0886^{\mathrm{T}}$ & JN846710 & JN846724 & JN846734 & - \\
\hline Fissuroma maculans & MFLUCC 11-0023 & JN846714 & JN846728 & JN846738 & _ \\
\hline Fissuroma neoaggregata & MFLUCC 10-0554 ${ }^{\mathrm{T}}$ & JN846718 & KT955470 & KT955450 & KT955432 \\
\hline Fissuroma palmae & MFLU 19-0820 & - & MN712336 & - & MN744229 \\
\hline Fissuroma taiwanense & FU30861 T & - & MG189605 & MG189607 & MG252072 \\
\hline Fissuroma thailandicum & MFLUCC 11-0206 & - & KT955473 & KT955453 & KT955435 \\
\hline Massaria gigantispora & M26 & HQ599397 & HQ599397 & HQ599447 & HQ599337 \\
\hline Massaria inquinans & M19 & HQ599402 & HQ599402 & HQ599444 & HQ599342 \\
\hline $\begin{array}{l}\text { Neoastrosphaeriella } \\
\text { aquatica }\end{array}$ & MFLUCC 18-0209 T & MK138710 & MK138829 & MK138789 & MK132866 \\
\hline $\begin{array}{l}\text { Neoastrosphaeriella } \\
\text { aquatica }\end{array}$ & MFLU 19-0816 & MN735993 & MN712337 & MN699323 & MN744230 \\
\hline $\begin{array}{l}\text { Neoastrosphaeriella } \\
\text { aquatica }\end{array}$ & MFLUCC 18-1531 & MN735994 & MN712338 & - & MN744231 \\
\hline $\begin{array}{l}\text { Neoastrosphaeriella } \\
\text { phoenicis }\end{array}$ & $\underset{T}{\operatorname{MFLUCC}} \mathbf{1 8 - 1 4 7 7}$ & MN735995 & MN712339 & MN699324 & MN744232 \\
\hline $\begin{array}{l}\text { Neoastrosphaeriella } \\
\text { krabiensis }\end{array}$ & MFLUCC 11-0022 & JN846711 & JN846727 & JN846735 & - \\
\hline $\begin{array}{l}\text { Neoastrosphaeriella } \\
\text { krabiensis }\end{array}$ & MFLUCC 11-0025 ${ }^{\mathrm{T}}$ & JN846715 & JN846729 & JN846739 & - \\
\hline Neoastrosphaeriella sp. & $\mathrm{A} 70$ & - & GU205213 & GU205233 & - \\
\hline $\begin{array}{l}\text { Neoastrosphaeriella } \\
\text { sribooniensis }\end{array}$ & MFLUCC $13-0834^{\mathrm{T}}$ & - & MF588997 & MF588987 & MF588977 \\
\hline Rimora mangrovei & JK 5246A & - & GU301868 & GU296193 & - \\
\hline
\end{tabular}

Abbreviations: BCC BIOTEC Culture Collection, Bangkok, Thailand; CBS Centraal Bureau voor Schimmel cultures, Utrecht, The Netherlands; MFLU Mae Fah Luang University Herbarium Collection; MFLUCC Mae 
Fah Luang University Culture Collection, Chiang Rai, Thailand; JK J. Kohlmeyer; KT K. Tanaka; SMH S.M. Huhndorf.

\section{Results}

\section{Phylogenetic analyses}

The multi-gene dataset comprised 39 taxa and 3548 characters (ITS: 822 bp; LSU: 870 bp; SSU: 982 bp; TEF1- $\alpha$ : 874 bp) after alignment including gaps. RAxML, MP and Bayesian analyses were conducted and resulted in generally congruent topologies, and the familial and generic assignments are similar to previous studies (Liu et al. 2011, Phookamsak et al. 2015, Wanasinghe et al. 2018, Zhang et al. 2018, 2019). RAxML analysis based on ITS, LSU, SSU and TEF1- $\alpha$ yielded the best scoring tree (Fig. 1) with a final optimization likelihood value of -17277.762165 . The matrix had 1195 distinct alignment patterns, with $30.16 \%$ undetermined characters or gaps. Estimated base frequencies were: $\mathrm{A}=0.243435, \mathrm{C}=0.249933, \mathrm{G}=0.281605, \mathrm{~T}=0.225027$; substitution rates $\mathrm{AC}=1.136319, \mathrm{AG}=3.245371, \mathrm{AT}=1.300447, \mathrm{CG}=1.299865, \mathrm{CT}=$ 8.692916, GT $=1.000000$; gamma distribution shape parameter $\alpha=0.706134$. Maximum parsimony analyses indicated that 2387 characters were constant, 351 variable characters parsimony-uninformative and 810 characters are parsimony-informative. A heuristic search yield one equally most parsimonious trees $(\mathrm{TL}=2680, \mathrm{CI}=0.633, \mathrm{RI}=0.723, \mathrm{RC}=0.458, \mathrm{HI}=0.367$ ).

The newly generated strains in this study are nested in the genera Fissuroma and Neoastrosphaeriella. Two taxa belonging to Fissuroma are closely related and can be recognized as two species, $F$. caryotae and a new species $F$. palmae. Two of the other three taxa clustered with Neoastrosphaeriella aquatica, and one formed a distinct lineage in Neoastrosphaeriella, which can be recognized as a new species $N$. phoenicis.

\section{Taxonomy}

Fissuroma caryotae Wanas., E.B.G. Jones \& K.D. Hyde, Mycological Progress 17(5): 579 (2018)

Facesoffungi number: FoF03608

Saprobic on rachides of palms. Sexual morph: Ascomata 600-630 $\mu \mathrm{m}$ long, 420-575 $\mu \mathrm{m}$ diam. on host surface, in vertical section 220-270 $\mu \mathrm{m}$ high, 425-560 $\mu \mathrm{m}$ diam., black, gregarious, coriaceous, conical, hemisphaerical, unilocular, semi-immersed to erumpent, beneath the host surface, base applanate and immersed. Ostioles central, periphysate, with carbonaceous slit-like opening. Peridium up to $60 \mu \mathrm{m}$ wide, black, thick at sides towards the apex, poorly developed at the base, base and corners comprising a mixture of host tissue and brown to hyaline fungal cells, arranged in a textura angularis to textura prismatica. Hamathecium up to $1.5 \mu \mathrm{m}$ wide, hyaline, filamentous, trabeculate pseudoparaphyses, anastomosing, embedded in a gelatinous matrix. Asci $110-160 \times 14-21 \mu \mathrm{m}(\bar{x}=139 \times 17.5 \mu \mathrm{m}, \mathrm{n}=22), 8$-spored, bitunicate, cylindric-clavate or obclavate, with short furcate to truncate pedicel, apex narrow and rounded, with an ocular chamber. Ascospores 40-54 $\times 6-9.5 \mu \mathrm{m}(\bar{x}=47 \times 8 \mu \mathrm{m}, \mathrm{n}=40)$, overlapping 1-3-seriate at the base, 1seriate at the apex, hyaline, fusiform with acute ends, 1-septate, constricted at the septum, smoothwalled, surrounded by a distinct thin sheath. Asexual morph: Undetermined.

Culture characteristics - Colonies growing well on PDA media and attaining a diameter about $2 \mathrm{~cm}$ after 21 days at $25^{\circ} \mathrm{C}$, circular, medium dense, tufted colony center elevated, white grayish mycelium, becoming obverse olive to gray-green, reverse dark green.

Material examined - THAILAND, Chiang Mai Province, Mae Taeng District, Pa Pae, Mushroom Research Center, on the petiole of Calamus sp. (Arecaceae), 24 August 2016, S.N. Zhang, SNT12 (MFLU 19-2280, living culture MFLUCC 16-1383).

Notes - Phylogenetic analyses results showed that one of the fissuroma-like strain cluster with Fissuroma caryotae with high statistical support (Fig. 1). The new collection is identified as Fissuroma caryotae found from Calamus sp., and its ascomatal morphology on host surface is 
similar to F. calami in Wanasinghe et al. (2018). However, the molecular data of the new isolate (MFLUCC 16-1383) is identical to the ex-type strain of F. caryotae (MFLUCC 17-1253), with only one nucleotide difference in the LSU rDNA and TEF1- $\alpha$ sequence data, respectively. Morphologically, the two $F$. caryotae specimens are also comparable in the average dimensions of asci $(139 \times 17.5 \mu \mathrm{m}$ vs. $137 \times 15.5 \mu \mathrm{m})$ and ascospores $(47 \times 8 \mu \mathrm{m}$ vs. $44 \times 7.5 \mu \mathrm{m})$. A new host record of $F$. caryotae is reported and its living culture is provided herein.

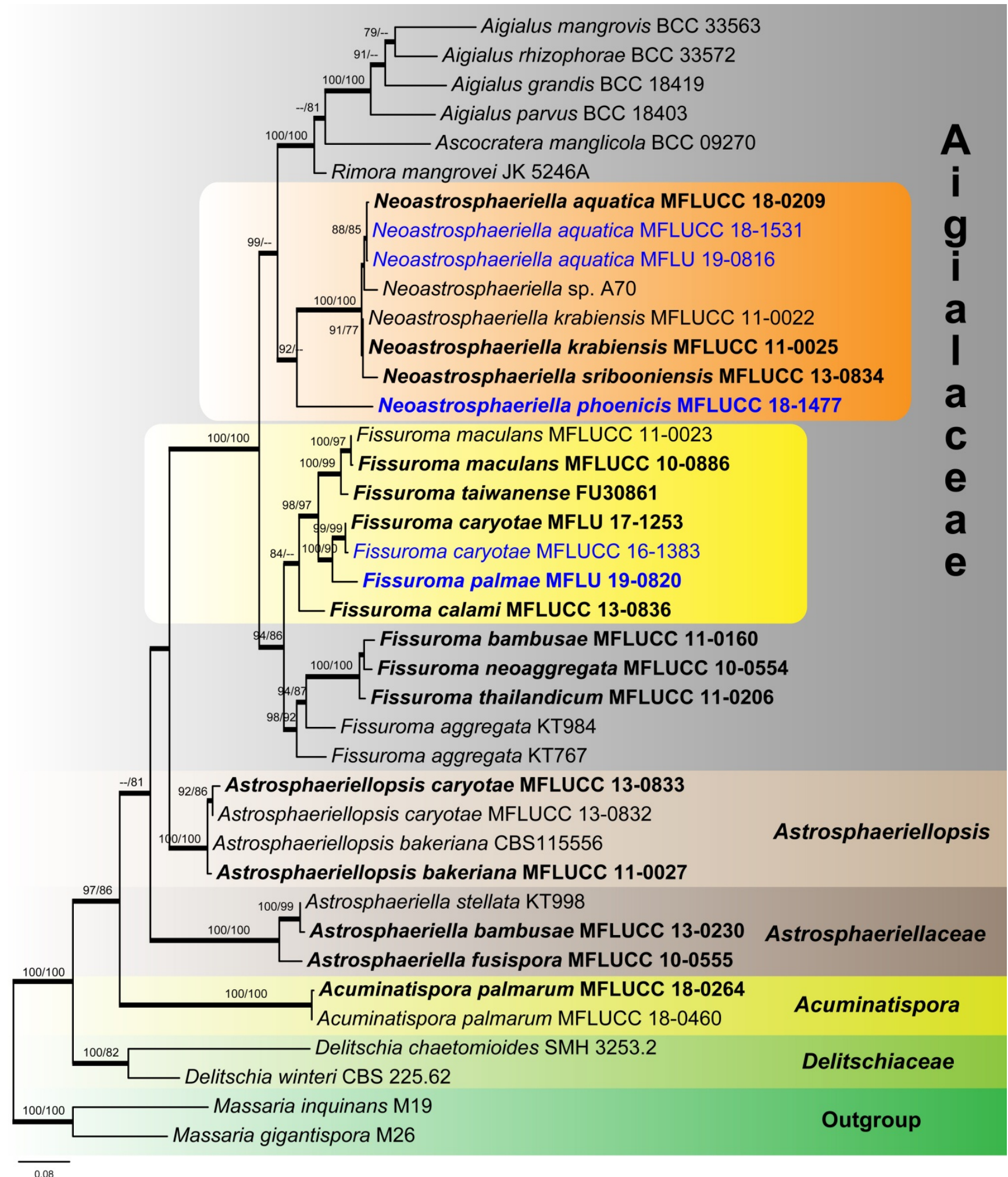

Figure 1 - RAxML tree of Aigialaceae and selected representative families in Pleosporales, based on analysis of ITS, LSU, SSU and TEF1- $\alpha$ gene region sequences data. Bootstrap values for ML 
and MP equal to or greater than $75 \%$ are placed (ML/MP) above the branches respectively. Branches with Bayesian posterior probabilities (PP) from MCMC analysis equal or greater than $0.95 \mathrm{PP}$ are in bold. The ex-type strains are in bold, and the new generated sequences are indicated in bold blue. The tree is rooted with Massaria gigantispora (M26) and M. inquinans (M19).
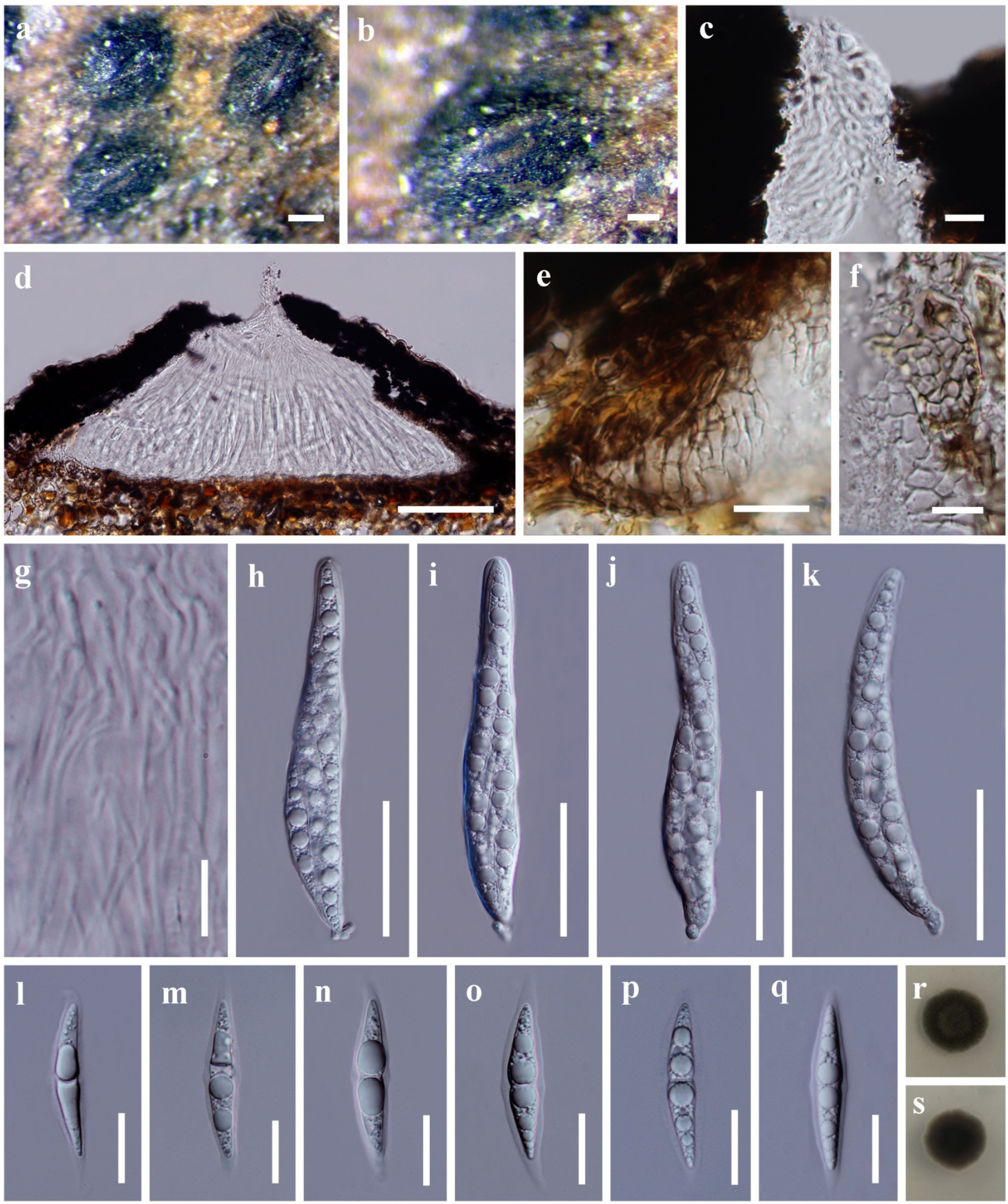

Figure 2 - Fissuroma caryotae (MFLU 19-2280). a, b Appearance of ascomata on host surface. c Ostiole with periphyses. d Vertical section of ascoma. e, f Structure of peridium. g Trabeculate 
pseudoparaphyses. $\mathrm{h}-\mathrm{k}$ Asci. 1-q Ascospores. $\mathrm{r}$, $\mathrm{s}$ Colony on PDA. Scale bars: $\mathrm{a}=200 \mu \mathrm{m}, \mathrm{b}, \mathrm{d}=$ $100 \mu \mathrm{m}, \mathrm{h}-\mathrm{k}=50 \mu \mathrm{m}, \mathrm{e}, \mathrm{l}-\mathrm{q}=20 \mu \mathrm{m}, \mathrm{c}, \mathrm{f}, \mathrm{g}=10 \mu \mathrm{m}$.

Fissuroma palmae S.N. Zhang, K.D. Hyde \& J.K. Liu, sp. nov.

Fig. 3

Index Fungorum number: IF556950; Facesoffungi number: FoF 06862

Etymology - The epithet refers to the general name of the host plant.

Holotype - MFLU 19-0820

Saprobic on rachides of palms. Sexual morph: Ascomata 410-760 $\mu \mathrm{m}$ long, 225-490 $\mu \mathrm{m}$ diam. on host surface, in vertical section 150-280 $\mu \mathrm{m}$ high, 380-480 $\mu \mathrm{m}$ diam., black, scattered, rarely clustered, coriaceous, conical, hemisphaerical, unilocular, semi-immersed to erumpent or superficial, form beneath the host surface, base applanate and immersed. Ostioles central, periphysate, with carbonaceous slit-like opening. Peridium 25-60 $\mu \mathrm{m}$ wide, black, thick at sides and thinner at the base, base and corners comprising hyaline to brown fungal cells, which arranged in a textura angularis. Hamathecium up to $1 \mu \mathrm{m}$ wide, hyaline, filamentous, trabeculate pseudoparaphyses, anastomosing, embedded in a gelatinous matrix. Asci $97-157 \times 14-24 \mu \mathrm{m}(\bar{x}=$ $121.5 \times 19.5 \mu \mathrm{m}, \mathrm{n}=30), 8$-spored, bitunicate, cylindric-clavate, short pedicellate, apically rounded with an ocular chamber. Ascospores 40-52 $\times 6-10 \mu \mathrm{m}(\bar{x}=45 \times 8.5 \mu \mathrm{m}, \mathrm{n}=30)$, overlapping, 2seriate, hyaline, becoming brown when mature or senescent, fusiform with acute ends, 1-septate, slightly constricted at the septum, smooth-walled, surrounded by a mucilaginous sheath. Sheath drawn out 3-6.5 $\mu \mathrm{m}$ long, 3.5-6.5 $\mu \mathrm{m}$ wide at both ends, up to $5.5 \mu \mathrm{m}$ at the middle. Asexual morph: Undetermined.

Material examined - THAILAND, Phang-nga Province, Thap Put District, Bo Sean, Tao Thong Waterfall, on the rachides of Arenga pinnata (Wurmb) Merr. (Arecaceae), 30 August 2017, S.N. Zhang, SNT253A (MFLU 19-0820, holotype; HKAS 105486, isotype).

Notes - Fissuroma palmae is different from other Fissuroma species in the dimensions of the asci and ascospores (Table 2). Phylogenetically, Fissuroma palmae clustered together with strains of $F$. caryotae (100\% ML, 90\% MP and $1.00 \mathrm{PP}$ ) but represented as a distinct lineage. In addition, the comparison of sequence data between the two species showed that there are 7 nucleotide differences across the 829 nucleotides $(0.84 \%)$ and 20 nucleotide differences across the 646 nucleotides $(3.1 \%)$ of LSU and TEF1- $\alpha$ respectively. Fissuroma palmae differs from $F$. caryotae in having cylindric-clavate asci, which is also shorter than that of $F$. caryotae in average dimension $(121.5 \times 19.5 \mu \mathrm{m}$ vs. $137 \times 15.5 \mu \mathrm{m}$ and $139 \times 17.5 \mu \mathrm{m})($ Table 2$)$.

Neoastrosphaeriella aquatica D.F. Bao, Z.L. Luo, K.D. Hyde \& H.Y. Su, Phytotaxa 391: 201 (2019)

Facesoffungi number: FoF04910

Saprobic on palms or decaying submerged wood in freshwater habitat. Sexual morph: Ascomata 280-450 $\mu \mathrm{m}$ long, 280-365 $\mu \mathrm{m}$ diam., in vertical section 210-250 $\mu \mathrm{m}$ high $\times 350-390$ $\mu \mathrm{m}$ long, black, coriaceous, slightly carbonaceous, unilocular, hemispherical, scattered, erumpent, semi-immersed to immersed, with a flattened base, beneath the host surface, with a central slit-like ostiole over almost the entire length. Ostioles slit-like, central. Peridium 25-65 $\mu \mathrm{m}$ wide, black, composed of dark brown thick-walled cells of textura angularis. Hamathecium 1-1.5 $\mu \mathrm{m}$ wide, trabeculate pseudoparaphyses, hyaline, anastomosing, embedded in a gelatinous matrix. Asci 90 $120 \times 10-20 \mu \mathrm{m}(\bar{x}=111 \times 16 \mu \mathrm{m}, \mathrm{n}=20), 8$-spored, bitunicate, fissitunicate, cylindric-clavate or obclavate, short pedicellate, apex narrow and rounded, with a small ocular chamber. Ascospores 30-40 $\times 5-8 \mu \mathrm{m}(\bar{x}=35.5 \times 6.5 \mu \mathrm{m}, \mathrm{n}=40)$, overlapping, 1-2-seriate, fusiform, hyaline when young, becoming brown and verrucose when mature, tapering to pointed apices, 1-septate, slightly constricted at the septum, surrounded by a mucilaginous sheath. Asexual morph: Undetermined.

Culture characteristics - Colonies growing well on PDA media and attaining a diameter about $3.5 \mathrm{~cm}$ after 21 days at $25^{\circ} \mathrm{C}$, medium dense, flattened colony, slightly radiating with concentric ring of cottony mycelium at edge of colony, obverse olive to gray-green, reverse dark green. 

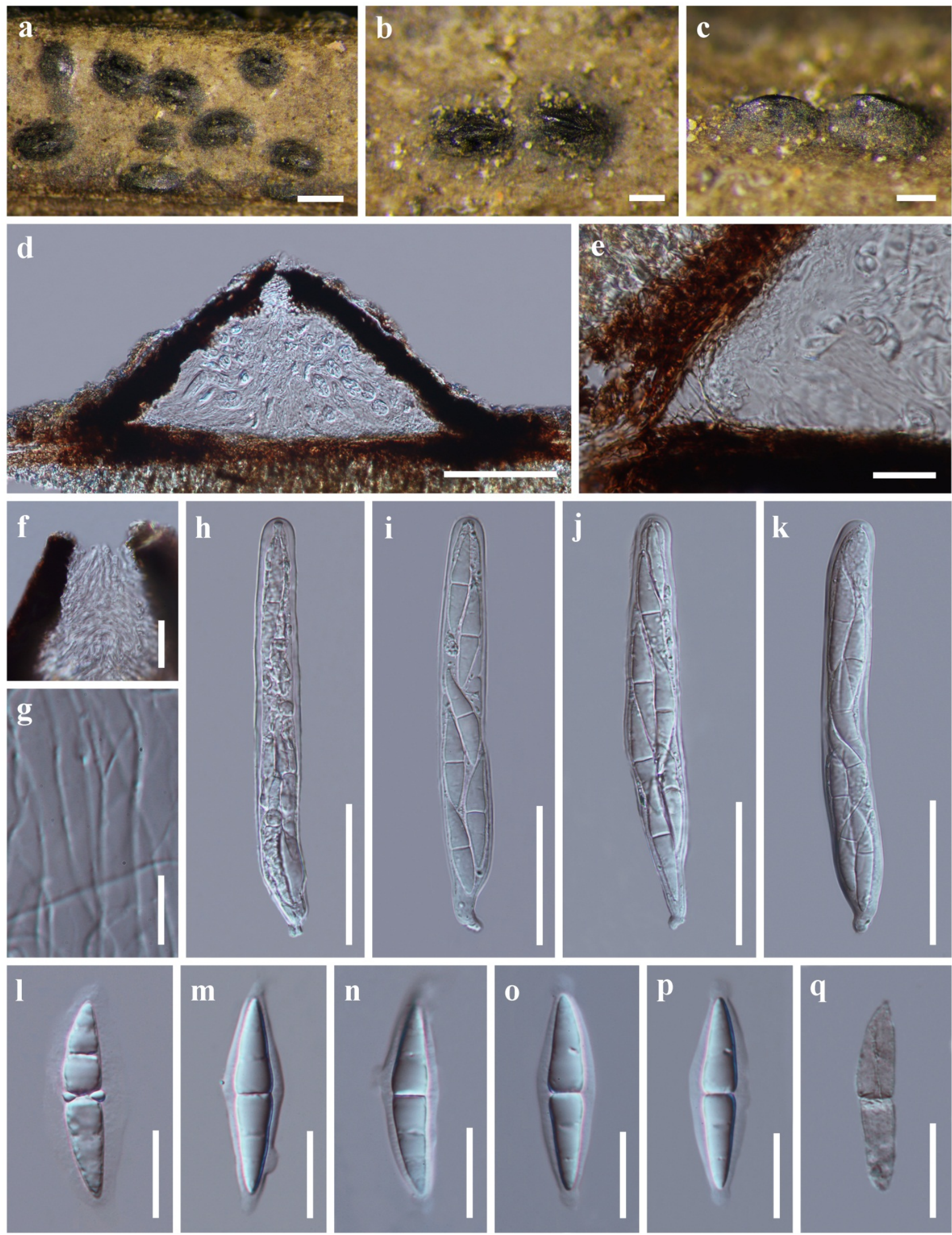

Figure 3 - Fissuroma palmae (MFLU 19-0820, holotype). a-c Appearance of ascomata on host surface. d Vertical section of ascoma. e Structure of peridium. f Ostiole with periphyses. g Trabeculate pseudoparaphyses. $\mathrm{h}-\mathrm{k}$ Asci. $\mathrm{l}-\mathrm{q}$ Ascospores. Scale bars: $\mathrm{a}=500 \mu \mathrm{m}, \mathrm{b}, \mathrm{c}=200 \mu \mathrm{m}, \mathrm{d}$ $=100 \mu \mathrm{m}, \mathrm{h}-\mathrm{k}=50 \mu \mathrm{m}, \mathrm{e}, \mathrm{f}, \mathrm{l}-\mathrm{q}=20 \mu \mathrm{m}, \mathrm{g}=10 \mu \mathrm{m}$. 
Table 2 The asci and ascospores morphology, habitats and host records of Fissuroma species.

\begin{tabular}{|c|c|c|c|c|c|c|}
\hline \multirow{2}{*}{ Taxa } & \multicolumn{2}{|c|}{ Asci } & \multicolumn{2}{|c|}{ Ascospores } & \multirow{2}{*}{$\begin{array}{l}\text { Habitats \& } \\
\text { host records }\end{array}$} & \multirow{2}{*}{ References } \\
\hline & Morphology & Size $(\mu \mathrm{m})$ & Morphology & Size $(\mu \mathrm{m})$ & & \\
\hline $\begin{array}{l}\text { Fissuroma } \\
\text { aggregata } \\
\text { (YAM } \\
20365, \\
\text { holotype) }\end{array}$ & Obclavate & $\begin{array}{l}143-185 \times \\
15-19.5(\bar{x} \\
=164.5 \times \\
17.3)\end{array}$ & $\begin{array}{l}\text { Hyaline, becoming } \\
\text { brown at maturity, } \\
\text { fusiform, 1- } \\
\text { septate, smooth- } \\
\text { walled, guttulate, } \\
\text { thin sheath }\end{array}$ & $\begin{array}{l}46-61(- \\
64) \times 7- \\
9.5(\bar{x}= \\
55.9 \times \\
8.2)\end{array}$ & $\begin{array}{l}\text { Terrestrial/ } \\
\text { Phyllostachys } \\
\text { bambusoides } \\
\text { (Poaceae) }\end{array}$ & $\begin{array}{l}\text { Phookamsak } \\
\text { et al. } 2015\end{array}$ \\
\hline $\begin{array}{l}F . \\
\text { bambusae } \\
\text { (MFLU 11- } \\
\text { 0196, } \\
\text { holotype) }\end{array}$ & $\begin{array}{l}\text { Cylindric-clavate } \\
\text { or obclavate }\end{array}$ & $\begin{array}{l}(150-) 170- \\
187(-194) \times \\
(15-) 17- \\
19(-22)(\bar{x} \\
=178.1 \times \\
18.5)\end{array}$ & $\begin{array}{l}\text { Hyaline, fusiform, } \\
\text { 1-septate, smooth- } \\
\text { walled, thick } \\
\text { sheath }\end{array}$ & $\begin{array}{l}(40-) 45- \\
47(-52) \times \\
6-8(-9) \\
(\bar{x}= \\
46.2 \times 7.1)\end{array}$ & $\begin{array}{l}\text { Terrestrial/ } \\
\text { Bamboo }\end{array}$ & $\begin{array}{l}\text { Phookamsak } \\
\text { et al. } 2015\end{array}$ \\
\hline $\begin{array}{l}\text { F. calami } \\
\text { (MFLU 17- } \\
1251, \\
\text { holotype) }\end{array}$ & $\begin{array}{l}\text { Cylindric-clavate } \\
\text { or obclavate }\end{array}$ & $\begin{array}{l}100-130 \times \\
19-22(\bar{x}= \\
120.3 \times \\
20.3)\end{array}$ & $\begin{array}{l}\text { Hyaline, fusiform, } \\
\text { 1-septate, smooth- } \\
\text { walled, guttulate, } \\
\text { thin sheath }\end{array}$ & $\begin{array}{l}40-45 \times \\
7-9(\bar{x}= \\
43.5 \times \\
8.2)\end{array}$ & $\begin{array}{l}\text { Terrestrial/ } \\
\text { Calamus } \\
\text { rotang } \\
\text { (Arecaceae) }\end{array}$ & $\begin{array}{l}\text { Wanasinghe } \\
\text { et al. } 2018\end{array}$ \\
\hline $\begin{array}{l}F . \text { caryotae } \\
\text { (MFLU 17- } \\
1253, \\
\text { holotype) }\end{array}$ & $\begin{array}{l}\text { Cylindric-clavate } \\
\text { or obclavate }\end{array}$ & $\begin{array}{l}120-150 \times \\
14-18(\bar{x}= \\
136.8 \times \\
15.4)\end{array}$ & $\begin{array}{l}\text { Hyaline, 1-septate, } \\
\text { fusiform with } \\
\text { acute ends, } \\
\text { smooth-walled, } \\
\text { thin sheath }\end{array}$ & $\begin{array}{l}40-50 \times \\
7-9(\bar{x}= \\
44.2 \times \\
7.5)\end{array}$ & $\begin{array}{l}\text { Terrestrial/ } \\
\text { Caryota urens } \\
\text { (Arecaceae) }\end{array}$ & $\begin{array}{l}\text { Wanasinghe } \\
\text { et al. } 2018\end{array}$ \\
\hline $\begin{array}{l}\text { F. caryotae } \\
\text { (MFLU 19- } \\
2280, \\
\text { reference } \\
\text { specimen) }\end{array}$ & $\begin{array}{l}\text { Cylindric-clavate } \\
\text { or obclavate }\end{array}$ & $\begin{array}{l}110-160 \times \\
14-21(\bar{x}= \\
139 \times 17.5)\end{array}$ & $\begin{array}{l}\text { Hyaline, 1-septate, } \\
\text { fusiform with } \\
\text { acute ends, } \\
\text { smooth-walled, } \\
\text { thin sheath }\end{array}$ & $\begin{array}{l}40-54 \times \\
6-9.5(\bar{x} \\
=47 \times 8)\end{array}$ & $\begin{array}{l}\text { Terrestrial/ } \\
\text { Calamus sp. } \\
\text { (Arecaceae) }\end{array}$ & This study \\
\hline $\begin{array}{l}F . \\
\text { fissuristom } \\
a \text { (IFRD } \\
294-002, \\
\text { holotype) }\end{array}$ & Obclavate & $\begin{array}{l}(124-) 130- \\
150(-166) \times \\
(16-) 18- \\
19(-26)(\bar{x} \\
=144.1 \times \\
19.3)\end{array}$ & $\begin{array}{l}\text { Hyaline, fusiform, } \\
\text { 1-septate, } \\
\text { becoming brown } \\
\text { with 3-septa at } \\
\text { maturity, thin } \\
\text { sheath }\end{array}$ & $\begin{array}{l}(43-) 45- \\
50(-55) \times \\
7-9(\bar{x}= \\
48.2 \times 8.4 \\
)\end{array}$ & $\begin{array}{l}\text { Terrestrial/ } \\
\text { Calamus } \\
\text { conirostris } \\
\text { (Arecaceae) }\end{array}$ & $\begin{array}{l}\text { Phookamsak } \\
\text { et al. } 2015\end{array}$ \\
\hline $\begin{array}{l}F . \\
\text { kavachabee } \\
\text { jae (AMH- } \\
9963, \\
\text { holotype) }\end{array}$ & Cylindrical & $\begin{array}{l}142-167 \times \\
15-20(\bar{x}= \\
153.3 \times 16.5 \\
)\end{array}$ & $\begin{array}{l}\text { Hyaline, fusiform, } \\
\text { 1-septate, smooth- } \\
\text { walled, guttulate, } \\
\text { with sheath }\end{array}$ & $\begin{array}{l}37.3-47.4 \\
\times 4.7- \\
6.7(-8.1) \\
(\bar{x}=42.1 \\
\times 6.2)\end{array}$ & $\begin{array}{l}\text { Terrestrial/ } \\
\text { Calamus } \\
\text { andamanicus } \\
\text { (Arecaceae) }\end{array}$ & $\begin{array}{l}\text { Niranjan \& } \\
\text { Sarma } 2018\end{array}$ \\
\hline $\begin{array}{l}F . \\
\text { maculans } \\
\text { (MFLU 11- } \\
\text { 1143, type } \\
\text { species) }\end{array}$ & $\begin{array}{l}\text { Cylindric-clavate } \\
\text { or obclavate }\end{array}$ & $\begin{array}{l}65-125 \times \\
10-17(\bar{x}= \\
85 \times 13)\end{array}$ & $\begin{array}{l}\text { Hyaline, fusiform, } \\
\text { 1-septate, smooth- } \\
\text { walled, with sheath }\end{array}$ & $\begin{array}{l}29-38 \times \\
4-8(\bar{x}= \\
30 \times 6.5)\end{array}$ & $\begin{array}{l}\text { Terrestrial/ } \\
\text { Arenga } \\
\text { westerhoutii } \\
\text { (Arecaceae), } \\
\text { Metroxylon } \\
\text { sagu } \\
\text { (Arecaceae) }\end{array}$ & $\begin{array}{l}\text { Liu et al. } \\
2011\end{array}$ \\
\hline $\begin{array}{l}F . \\
\text { microsporu } \\
m \text { (AMH- } \\
9962, \\
\text { holotype) }\end{array}$ & $\begin{array}{l}\text { Cylindrical, } \\
\text { Cylindric-oblong }\end{array}$ & $\begin{array}{l}(75.9- \\
) 80.3-103.6 \\
\times 7.4-8.7 \\
(\bar{x}=94 \times \\
8.4)\end{array}$ & $\begin{array}{l}\text { Hyaline, fusiform } \\
\text { with 1-septate, 2-3 } \\
\text { pseudo-septa, with } \\
\text { thick sheath and } \\
\text { polar appendages }\end{array}$ & $\begin{array}{l}14.6-21.8 \\
\times 3.5-4 \\
(\bar{x}=18.7 \\
\times 3.2)\end{array}$ & $\begin{array}{l}\text { Terrestrial/ } \\
\text { Borassus } \\
\text { flabellifer } \\
\text { (Arecaceae) }\end{array}$ & $\begin{array}{l}\text { Niranjan \& } \\
\text { Sarma } 2018\end{array}$ \\
\hline
\end{tabular}


Table 2 Continued.

\begin{tabular}{|c|c|c|c|c|c|c|}
\hline \multirow{2}{*}{ Taxa } & \multicolumn{2}{|c|}{ Asci } & \multicolumn{2}{|c|}{ Ascospores } & \multirow{2}{*}{$\begin{array}{l}\text { Habitats \& } \\
\text { host records }\end{array}$} & \multirow{2}{*}{ References } \\
\hline & Morphology & Size $(\mu \mathrm{m})$ & Morphology & Size $(\mu \mathrm{m})$ & & \\
\hline$F$. & Cylindric-clavate & $155-197 \times$ & Hyaline, elongate- & $38.5-54 \times$ & Terrestrial/ & Liu et al. \\
\hline $\begin{array}{l}\text { neoaggrega } \\
\text { ta (MFLU } \\
11-0146, \\
\text { holotype) }\end{array}$ & or obclavate & $\begin{array}{l}15-18.5(\bar{x} \\
=177 \times \\
16.5)\end{array}$ & $\begin{array}{l}\text { fusiform, 1-septate, } \\
\text { smooth-walled, } \\
\text { guttulate, with } \\
\text { sheath }\end{array}$ & $\begin{array}{l}7-10.5(\bar{x} \\
=47.5 \times \\
8.5)\end{array}$ & Bamboo & $\begin{array}{l}2011, \\
\text { Phookamsak } \\
\text { et al. } 2015\end{array}$ \\
\hline $\begin{array}{l}F . \text { palmae } \\
\text { (MFLU 19- } \\
\text { 0820, } \\
\text { holotype) }\end{array}$ & Cylindric-clavate & $\begin{array}{l}97-157 \times \\
14-24(\bar{x}= \\
121.5 \times \\
19.5)\end{array}$ & $\begin{array}{l}\text { Hyaline, becoming } \\
\text { brown when } \\
\text { mature or } \\
\text { senescent, } \\
\text { fusiform, 1-septate, } \\
\text { smooth-walled, } \\
\text { thin sheath }\end{array}$ & $\begin{array}{l}40-52 \times \\
6-10(\bar{x}= \\
45 \times 8.5)\end{array}$ & $\begin{array}{l}\text { Terrestrial/ } \\
\text { Arenga pinnata } \\
\text { (Arecaceae) }\end{array}$ & This study \\
\hline $\begin{array}{l}F . \\
\text { taiwanense } \\
\text { (F31005, } \\
\text { holotype) }\end{array}$ & $\begin{array}{l}\text { Broadly } \\
\text { cylindrical to } \\
\text { obclavate }\end{array}$ & $\begin{array}{l}(97-) 100- \\
120(-125) \times \\
(23.5-) 24- \\
29(-30)(\bar{x} \\
=110 \times \\
26.5)\end{array}$ & $\begin{array}{l}\text { Hyaline, fusiform, } \\
\text { 1-septate, smooth- } \\
\text { walled, thick } \\
\text { sheath, with club- } \\
\text { shaped appendages }\end{array}$ & $\begin{array}{l}52-56 \times \\
8.5-10(\bar{x} \\
=53.5 \times \\
9.4)\end{array}$ & $\begin{array}{l}\text { Terrestrial/ } \\
\text { Hedychium } \\
\text { coronarium } \\
\text { (Zingiberaceae } \\
\text { ) }\end{array}$ & $\begin{array}{l}\text { Tennakoon et } \\
\text { al. } 2018\end{array}$ \\
\hline $\begin{array}{l}F . \\
\text { thailandicu } \\
m \text { (MFLU } \\
11-0156, \\
\text { holotype) }\end{array}$ & $\begin{array}{l}\text { Cylindrical to } \\
\text { cylindric-clavate }\end{array}$ & $\begin{array}{l}(150-) 170- \\
190(-204) \times \\
15-18(- \\
19.5)(\bar{x}= \\
176.9 \times 17)\end{array}$ & $\begin{array}{l}\text { Hyaline, fusiform, } \\
\text { 1-septate, smooth- } \\
\text { walled, thick } \\
\text { sheath }\end{array}$ & $\begin{array}{l}(40-) 43- \\
46(-52) \times \\
6-7(-9) \\
(\bar{x}=45.4 \\
\times 7.1)\end{array}$ & $\begin{array}{l}\text { Terrestrial/ } \\
\text { Bamboo }\end{array}$ & $\begin{array}{l}\text { Phookamsak } \\
\text { et al. } 2015\end{array}$ \\
\hline
\end{tabular}

Material examined - THAILAND, Phang-nga Province, Kapong District, Mo, on the petiole of Metroxylon sagu Rottb. (Arecaceae), 29 August 2017, S.N. Zhang, SNT190 (MFLU 19-0816= HKAS 105481); ibid., on the rachides of palm species, 29 August 2017, S.N. Zhang, SNT240 (MFLU 19-0819, HKAS 105485), living culture MFLUCC 18-1531.

Notes - Neoastrosphaeriella aquatica was introduced by Bao et al. (2019). In this study, our two newly collected isolates clustered together with $N$. aquatica (Fig. 1). The comparison of sequence data of these three strains showed that there is only one nucleotide difference in the ITS regions and one gap in the TEF1- $\alpha$ sequence data. We identify them as Neoastrosphaeriella aquatica based on the morphology (Table 3) and phylogeny, and report the new habitats and host record for N. aquatica.

Neoastrosphaeriella phoenicis S.N. Zhang, E.B.G. Jones \& J.K. Liu, sp. nov.

Fig.5

Index Fungorum number: IF556951; Facesoffungi number: FoF06863

Etymology - The epithet refers to the host plant, of which the fungus was collected.

Holotype - MFLU 19-0807

Saprobic on palm in mangrove habitat. Sexual morph: Ascomata 535-730 $\mu \mathrm{m}$ long, 350-505 $\mu \mathrm{m}$ diam., in vertical section 260-295 $\mu \mathrm{m}$ high, 360-415 $\mu \mathrm{m}$ long, black, coriaceous, slightly carbonaceous, unilocular, hemispherical, scattered, erumpent, semi-immersed to immersed, with a flattened base, beneath the host surface, with a central slit-like ostiole over almost the entire length, base applanate and immersed. Ostioles central, slit-like opening. Peridium 40-80 $\mu \mathrm{m}$ wide, the outside layer black, with host cells and fungal tissue, and the inner layer thin, comprising fungal cells of textura angularis, thinner at the base. Hamathecium 1-1.5 $\mu \mathrm{m}$ wide, trabeculate pseudoparaphyses, hyaline, anastomosing, embedded in a gelatinous matrix. Asci 110-130 × 15-22 $\mu \mathrm{m}(\bar{x}=121 \times 19.5 \mu \mathrm{m}, \mathrm{n}=15), 8$-spored, fissitunicate, obclavate, short pedicellate, apex narrow and rounded, with a small ocular chamber. Ascospores 40-60 $\times 6-11 \mu \mathrm{m}(\bar{x}=49 \times 8 \mu \mathrm{m}, \mathrm{n}=20)$, 1-2 seriate, fusiform, hyaline when young, becoming brown to dark brown and verrucose when mature or senescent, tapering to pointed apices, 1-3-septate, constricted at the septum, surrounded 
by a mucilaginous sheath 1-2 $\mu \mathrm{m}$ wide, which is slightly drawn out at the apices. Asexual morph: Undetermined.
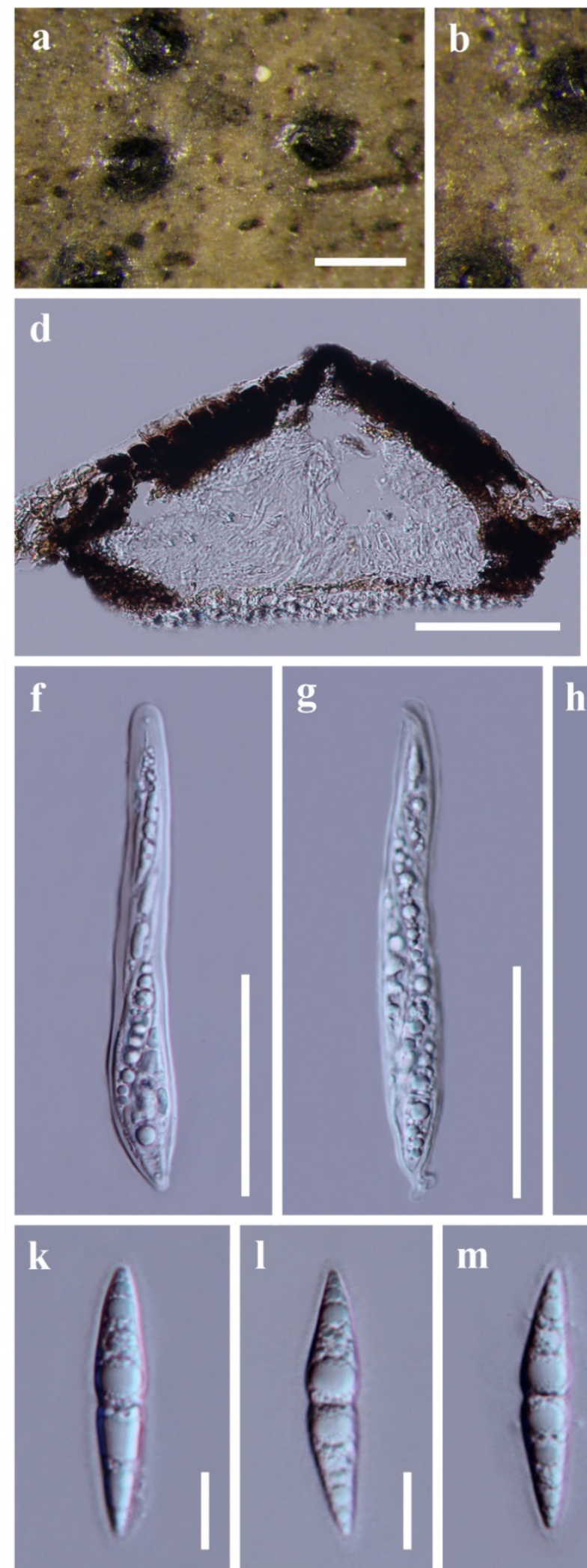


Figure 4 - Neoastrosphaeriella aquatica (MFLU 19-0816, MFLU19-0819). a, b Appearance of ascomata on host surface. c Structure of peridium. d, e Vertical section of ascoma. $\mathrm{f}-\mathrm{h}$ Asci. i Pseudoparaphyses. $\mathrm{j}-\mathrm{n}$ Ascospores; $\mathrm{j}$ ascospore in India ink showing sheath. $\mathrm{o}, \mathrm{p}$ Colonies on PDA. Scale bars: $\mathrm{a}=500 \mu \mathrm{m}, \mathrm{b}=200 \mu \mathrm{m}, \mathrm{d}, \mathrm{e}=100 \mu \mathrm{m}, \mathrm{f}-\mathrm{h}=50 \mu \mathrm{m}, \mathrm{c}, \mathrm{j}=20 \mu \mathrm{m}, \mathrm{i}, \mathrm{k}-\mathrm{n}=10 \mu \mathrm{m}$. 
Table 3 The asci and ascospores morphology, habitats and host records of Neoastrosphaeriella species.

\begin{tabular}{|c|c|c|c|c|c|c|}
\hline \multirow{2}{*}{ Taxa } & \multicolumn{2}{|c|}{ Asci } & \multicolumn{2}{|c|}{ Ascospores } & \multirow{2}{*}{$\begin{array}{l}\text { Habitats \& } \\
\text { host records }\end{array}$} & \multirow{2}{*}{ References } \\
\hline & Morphology & Size $(\mu \mathrm{m})$ & Morphology & Size $(\mu \mathrm{m})$ & & \\
\hline $\begin{array}{l}N . \\
\text { alankrithab } \\
\text { eejae } \\
\text { (AMH- } \\
9961, \\
\text { holotype) }\end{array}$ & $\begin{array}{l}\text { Cylindrical, } \\
\text { obclavate }\end{array}$ & $\begin{array}{l}132.2-154.5 \\
\times(19.2- \\
) 21.1-32.5 \\
(\bar{x}=143.5 \\
\times 25.4)\end{array}$ & $\begin{array}{l}\text { Hyaline to pale- } \\
\text { brown at maturity, } \\
\text { broad-fusiform, 1- } \\
\text { septate with two } \\
\text { pseudo-septa, } \\
\text { verrucose }\end{array}$ & $\begin{array}{l}40.2-46.7 \\
\times 8.5- \\
9.3(-10) \\
(\bar{x}=44.2 \\
\times 9)\end{array}$ & $\begin{array}{l}\text { Terrestrial / } \\
\text { Calamus } \\
\text { andamanicus } \\
\text { (Arecaceae) }\end{array}$ & $\begin{array}{l}\text { Niranjan \& } \\
\text { Sarma } 2018\end{array}$ \\
\hline $\begin{array}{l}\text { N. aquatica } \\
\text { (MFLU 18- } \\
1392, \\
\text { holotype) }\end{array}$ & $\begin{array}{l}\text { Cylindric-clavate } \\
\text { or obclavate }\end{array}$ & $\begin{array}{l}84-112 \times \\
14-19(\bar{x}= \\
98 \times 15.7)\end{array}$ & $\begin{array}{l}\text { Hyaline, grayish } \\
\text { brown and } \\
\text { verrucose at } \\
\text { maturity, fusiform, } \\
\text { 1-septate }\end{array}$ & $\begin{array}{l}31-37 \times \\
5-8(\bar{x}= \\
34 \times 6.4)\end{array}$ & $\begin{array}{l}\text { Freshwater / } \\
\text { submerged } \\
\text { wood in } \\
\text { freshwater }\end{array}$ & Bao et al. 2019 \\
\hline $\begin{array}{l}\text { N. aquatica } \\
\text { (MFLU 19- } \\
0816, \\
\text { MFLU 19- } \\
0819, \\
\text { reference } \\
\text { specimens) }\end{array}$ & $\begin{array}{l}\text { Cylindric-clavate } \\
\text { or obclavate }\end{array}$ & $\begin{array}{l}90-120 \times \\
10-20(\bar{x}= \\
111 \times 16)\end{array}$ & $\begin{array}{l}\text { Hyaline, becoming } \\
\text { brown and } \\
\text { verrucose when } \\
\text { mature, fusiform, } \\
\text { 1-septate }\end{array}$ & $\begin{array}{l}30-40 \times \\
5-8(\bar{x}= \\
35.5 \times \\
6.5)\end{array}$ & $\begin{array}{l}\text { Terrestrial/ } \\
\text { Metroxylon } \\
\text { sagu } \\
\text { (Arecaceae) }\end{array}$ & This study \\
\hline $\begin{array}{l}N . \\
\text { krabiensis } \\
\text { (MFLU 11- } \\
1148, \\
\text { holotype) }\end{array}$ & Obclavate & $\begin{array}{l}85-135 \times \\
15-23(\bar{x}= \\
100 \times 18)\end{array}$ & $\begin{array}{l}\text { Hyaline, becoming } \\
\text { brown and } \\
\text { verrucose when } \\
\text { mature, fusiform, } \\
\text { 1-septate }\end{array}$ & $\begin{array}{l}32-40 \times \\
6-9(\bar{x}= \\
35.5 \times 7)\end{array}$ & $\begin{array}{l}\text { Terrestrial/ } \\
\text { Metroxylon } \\
\text { sagu } \\
\text { (Arecaceae), } \\
\text { Elaeis } \\
\text { guineensis } \\
\text { (Arecaceae) }\end{array}$ & Liu et al. 2011 \\
\hline $\begin{array}{l}N . \\
\text { sribooniensi } \\
s \text { (MFLU } \\
17-1254, \\
\text { holotype) }\end{array}$ & $\begin{array}{l}\text { Cylindric-clavate } \\
\text { or obclavate }\end{array}$ & $\begin{array}{l}90-110 \times \\
15-18(\bar{x}= \\
99.5 \times 16.9)\end{array}$ & $\begin{array}{l}\text { Hyaline, fusiform, } \\
\text { 1-septate, smooth- } \\
\text { walled }\end{array}$ & $\begin{array}{l}30-40 \times \\
5-7(\bar{x}= \\
37.8 \times \\
6.3)\end{array}$ & $\begin{array}{l}\text { Terrestrial/ } \\
\text { Calamus } \\
\text { rotang } \\
\text { (Arecaceae) }\end{array}$ & $\begin{array}{l}\text { Wanasinghe et } \\
\text { al. } 2018\end{array}$ \\
\hline $\begin{array}{l}\text { N. phoenicis } \\
\text { (MFLU 19- } \\
\text { 0807, } \\
\text { holotype) }\end{array}$ & Obclavate & $\begin{array}{l}110-130 \times \\
15-22(\bar{x}= \\
121 \times 19.5)\end{array}$ & $\begin{array}{l}\text { Hyaline, becoming } \\
\text { brown and } \\
\text { verrucose when } \\
\text { mature, fusiform, } \\
\text { 1-3-septate }\end{array}$ & $\begin{array}{l}40-60 \times \\
6-11(\bar{x}= \\
49 \times 8)\end{array}$ & $\begin{array}{l}\text { Mangrove / } \\
\text { Phoenix } \\
\text { paludosa } \\
\text { (Arecaceae) }\end{array}$ & This study \\
\hline
\end{tabular}

Culture characteristics - Colonies growing well on PDA media and attaining a diameter about 3-4 cm after 21 days at $25^{\circ} \mathrm{C}$, flattened colony, slightly radiating with concentric ring of cottony mycelium at edge of colony, obverse gray-green, reverse dark green.

Material examined - THAILAND, Ranong Province, Ranong District, Ngao, Ngao mangrove forest research center, on the petiole of Phoenix paludosa Roxb. (Arecaceae), immersed in mangrove mud and water, 7 December 2016, S.N. Zhang, SNT59 (MFLU 19-0807, holotype; HKAS105449, isotype), ex-type living culture MFLUCC 18-1477.

Notes - Neoastrosphaeriella phoenicis was collected from a mangrove habitat, and is different from other species by having hyaline to pale brown, 1-3-septate, guttulate, verrucose ascospores (Fig. 5, Table 3). Neoastrosphaeriella phoenicis morphologically resembles $N$. alankrithabeejae (Niranjan \& Sarma 2018), which presents two pseudo-septa but lacks molecular data. However, Neoastrosphaeriella phoenicis differs from N. alankrithabeejae in having smaller, obclavate asci $(110-130 \times 15-22 \mu \mathrm{m}$ vs. $132-154.5 \times(19.2-)$ 21-32.5 $\mu \mathrm{m})$ and 3-septate ascospores (Fig. 5o). The phylogenetic result (Fig. 1) showed that N. phoenicis clustered together with other Neoastrosphaeriella taxa which formed a monophyletic clade, while the isolate of $N$. 
phoenicis formed a distinct lineage (with 29 nucleotide differences across the 813 nucleotides of LSU sequence data) in Neoastrosphaeriella clade and can be recognized as a new species.
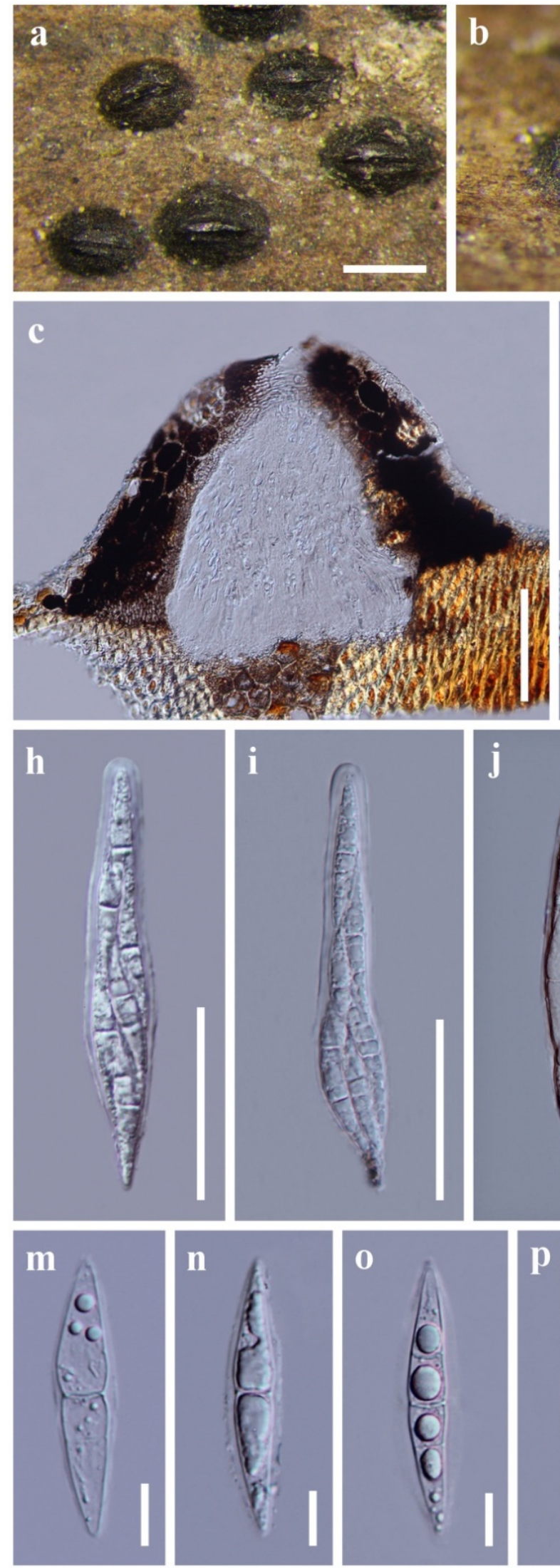
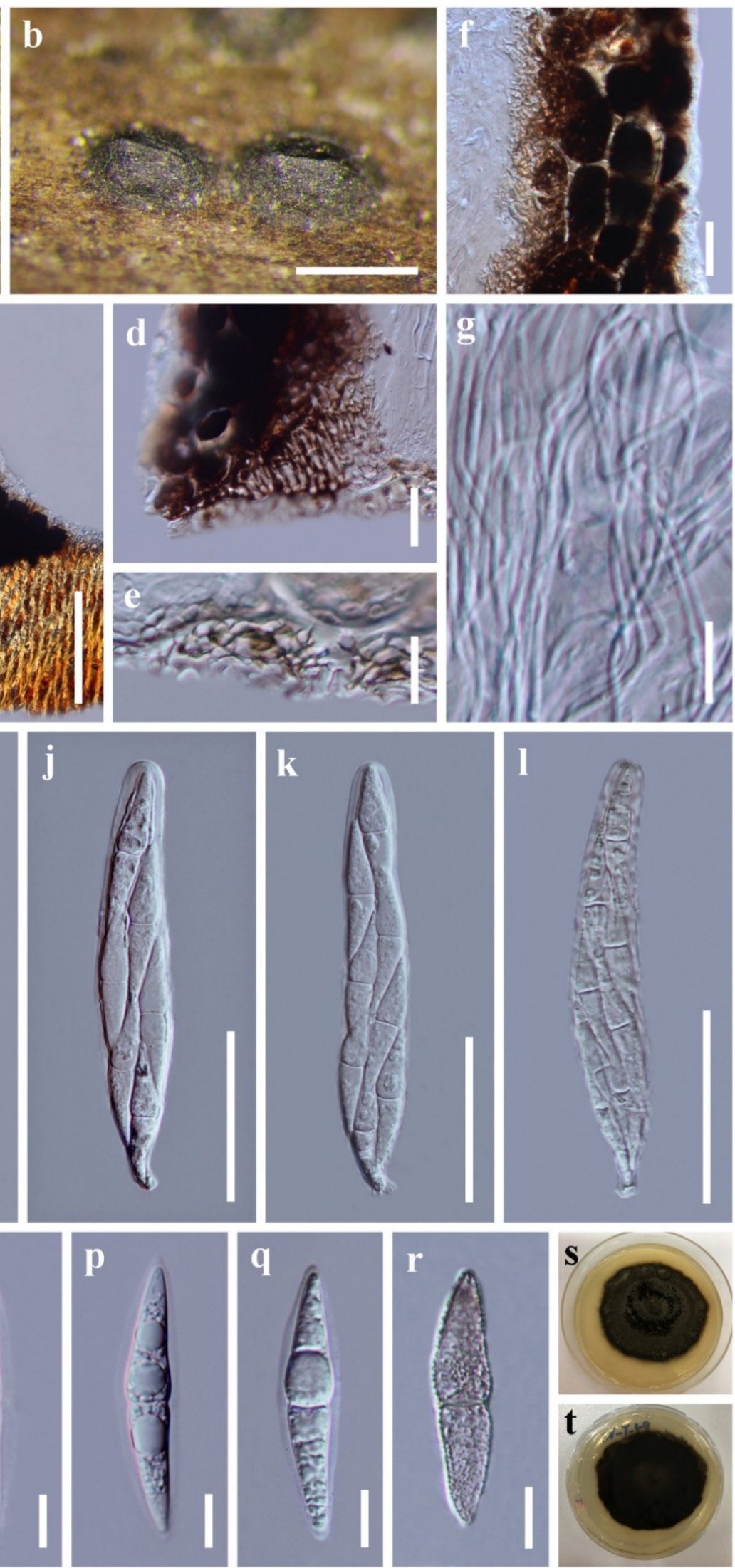

Figure 5 - Neoastrosphaeriella phoenicis (MFLU 19-0807, holotype). a, b Appearance of ascomata on host surface. c Vertical section of ascoma. $\mathrm{d}-\mathrm{f}$ Structure of peridium. $\mathrm{g}$ Trabeculate 
pseudoparaphyses. $\mathrm{h}-1$ Asci. $\mathrm{m}-\mathrm{r}$ Ascospores. $\mathrm{s}$, t Colony on PDA. Scale bars: $\mathrm{a}, \mathrm{b}=500 \mu \mathrm{m}, \mathrm{c}=$ $100 \mu \mathrm{m}, \mathrm{h}-\mathrm{l}=50 \mu \mathrm{m}, \mathrm{d}, \mathrm{f}=20 \mu \mathrm{m}, \mathrm{e}, \mathrm{g}, \mathrm{m}-\mathrm{r}=10 \mu \mathrm{m}$.

\section{Discussion}

Fissuroma and Neoastrosphaeriella were established by Liu et al. (2011) in a phylogenetic study of Astrosphaeriella sensu lato in Aigialaceae. Neoastrosphaeriella was considered to be different from Fissuroma in having smaller obclavate asci and brown verrucose ascosproes, and the two genera were distinguished by the shape (cylindric-clavate, obclavate) of asci, and the colour (hyaline, brown) and ornamentation (smooth, verrucose) of ascospores (Liu et al. 2011). However, the morphological characteristics of the two genera overlap when more taxa have been included in subsequent studies (Phookamsak et al. 2015, Niranjan \& Sarma 2018, Tennakoon et al. 2018, Wanasinghe et al. 2018, Bao et al. 2019). For example, brown mature ascospores were found in Fissuroma fissuristoma (三 Astrosphaeriella fissuristoma) (Phookamsak et al. 2015) and F. palmae (this study), and cylindric-clavate asci were found in N. alankrithabeejae (Niranjan \& Sarma 2018) and $N$. aquatica (Bao et al. 2019). Morphological features may differ depending on the state (mature or immature) of the specimen being observed, while DNA sequence data is more objective. The comparison of nucleotides difference of TEF1- $\alpha$ region was commonly used for delineating Fissuroma species, such as the identification of $F$. bambusae, F. neoaggregata, $F$. thailandicum (Phookamsak et al. 2015); F. calami and F. caryotae (Wanasinghe et al. 2018).

There are twelve Fissuroma and five Neoastrosphaeriella species described, including the new members Fissuroma palmae and Neoastrosphaeriella phoenicis in this study. Seven of the Fissuroma species are from terrestrial palms, and all the Neoastrosphaeriella species have been collected from palms (Tables 2, 3). It is possible to find the same species (e.g. F. maculans) from different palm hosts, and also discover the morphologically similar but different species (e.g. $F$. calami vs. N. sribooniensis) from the same palm host.

Members of Neoastrosphaeriella have been found from terrestrial and freshwater habitats. We report a new species, $N$. phoenicis, which was collected from the decayed petiole of Phoenix paludosa (mangrove date palm) that grows in soft mangrove mud and salty water. Thus, the species $N$. phoenicis can be considered as manglicolous, and additional mangrove habitat for the genus Neoastrosphaeriella is reported.

\section{Acknowledgements}

This study is supported by the Science and Technology Foundation of Guizhou Province (LH [2015]7061) in facilities and materials of molecular work. Kevin D. Hyde thanks to the grant the Thailand Research Fund (Grant No. RSA5980068). Gareth Jones acknowledges the award of a Distinguished Scientist Fellowship Program (DSFP), King Saud University, Kingdom of Saudi Arabia. The authors also would like to thank the staff of Ngao Mangrove Forest Research Center for their assistance in sample collection.

\section{References}

Bao DF, Luo ZL, Jeewon R, Nalumpang S et al. 2019 - Neoastrosphaeriella aquatica sp. nov. (Aigialaceae), a new species from freshwater habitat in southern Thailand. Phytotaxa 391, 197-206.

Chomnunti P, Hongsanan S, Aguirre-Hudson B, Tian Q et al. 2014 - The sooty moulds. Fungal Diversity 66, 1-36.

Hall TA. 1999 - BioEdit: a user-friendly biological sequence alignment editor and analysis program for Windows 95/98/NT. Nucleic Acids Symposium Series 41, 95-98.

Hyde KD, Jones EBG, Liu JK, Ariyawansa HA et al. 2013 - Families of Dothideomycetes. Fungal Diversity 63, 1-313.

Jayasiri SC, Hyde KD, Ariyawansa HA, Bhat JD et al. 2015 - The Faces of Fungi database: fungal names linked with morphology, phylogeny and human impacts. Fungal Diversity 74, 3-18. 
Jeewon R, Hyde KD. 2016 - Establishing species boundaries and new taxa among fungi: recommendations to resolve taxonomic ambiguities. Mycosphere 7, 1669-1677.

Katoh K, Standley DM. 2013 - MAFFT multiple sequence alignment software version 7: improvements in performance and usability. Molecular Biology and Evolution 30, 772-780.

Kohlmeyer J. 1986 - Ascocratera manglicola gen. et sp. nov. and key to the marine Loculoascomycetes on mangroves. Canadian Journal of Botany 64, 3036-3042.

Kohlmeyer J, Vittal BPR. 1986 - Lophiostoma mangrovis, a new marine ascomycete from the tropics. Mycologia 78, 489-492.

Liu JK, Chomnunti P, Cai L, Phookamsak R et al. 2010 - Phylogeny and morphology of Neodeightonia palmicola sp. nov. from palms. Sydowia 62, 261-276.

Liu JK, Phookamsak R, Jones EBG, Zhang Y et al. 2011 - Astrosphaeriella is polyphyletic, with species in Fissuroma gen. nov., and Neoastrosphaeriella gen. nov. Fungal Diversity 51, 135 154.

Niranjan M, Sarma VV. 2018 - New Ascomycetous fungi in the family Aigialaceae from Andaman Islands, India. Current Research in Environmental \& Applied Mycology 8, 351-359.

Phookamsak R, Norphanphoun C, Tanaka K, Dai DQ et al. 2015 - Towards a natural classification of Astrosphaeriella-like species; introducing Astrosphaeriellaceae and Pseudoastrosphaeriellaceae fam. nov. and Astrosphaeriellopsis, gen. nov. Fungal Diversity 74, 143-197.

Rambaut A. 2014 - FigTree 1.4.2. http://tree.bio.ed.ac.uk/software/figtree

Rehner SA. 2001 - Primers for Elongation Factor 1- $\alpha$ (EF1- $\alpha)$. Available at: http://ocid.nacse.org/research/deephyphae/EF1primer.pdf.

Suetrong S, Schoch CL, Spatafora JW, Kohlmeyer J et al. 2009 - Molecular systematics of the marine Dothideomycetes. Studies in Mycology 64, 155-173.

Tennakoon DS, Phookamsak R, Kuo CH, Goh TK et al. 2018 - Morphological and phylogenetic evidence reveal Fissuroma taiwanense sp. nov. (Aigialaceae, Pleosporales) from Hedychium coronarium. Phytotaxa 338, 265-275.

Vilgalys R, Hester M. 1990 - Rapid genetic identification and mapping of enzymatically amplified ribosomal DNA from several Cryptococcus species. Journal of Bacteriology 172, 4238-4246.

Wanasinghe DN, Jeewon R, Jones EBG, Boonmee S et al. 2018 - Novel palmicolous taxa within Pleosporales: multigene phylogeny and taxonomic circumscription. Mycological Progress 17, 571-590.

White TJ, Bruns T, Lee S, Taylor J. 1990 - Amplification and direct sequencing of fungal ribosomal RNA genes for phylogenetics. In: Innis MA, Gelfand DH, Sninsky JJ, White TJ (Eds) PCR protocols: a guide to methods and applications. Academic Press, Inc., New York.

Zhang Y, Crous PW, Schoch CL, Hyde KD. 2012 - Pleosporales. Fungal Diversity 53, 1-221.

Zhang SN, Hyde KD, Jones EBG, Cheewangkoon R, Liu JK. 2018 - Acuminatispora palmarum gen. et sp. nov. from mangrove habitats. Mycological Progress 17, 1173-1188.

Zhang SN, Hyde KD, Jones EBG, Jeewon R et al. 2019 - Striatiguttulaceae, a new pleosporalean family to accommodate Longicorpus and Striatiguttula gen. nov. from palms. MycoKeys 49, 99-129. 